\title{
LAS TEMPORALIDADES URBANAS DE BARCELONA DESPUÉS DE LA EXPULSIÓN DE LOS JESUITAS ${ }^{1}$
}

\author{
CARlos A. MARTÍNEZ TORNERO
}

Universidad de Alicante

\section{INTRODUCCIÓN}

En la primavera de 1767 Carlos III decretó la expulsión de los jesuitas de todos sus dominios de la península y ultramar. No se trataba solamente de la extirpación del reino del conjunto de religiosos a los que tanto temía después de los motines sucedidos durante el año anterior, entre los que adquirió una especial relevancia el sucedido en la capital (conocido como motín de Esquilache) pero que se repitió en diferentes provincias, si bien con una naturaleza distinta. El monarca situó en un mismo plano destierro y ocupación de temporalidades, es decir, el embargo de todas sus propiedades muebles e inmuebles y sus rentas eclesiásticas. De esta manera, el desalojo del país de los hijos de San Ignacio adquiría una dimensión económica que se sumaba a las razones políticas esgrimidas por los máximos defensores de la medida. Al mismo tiempo, se trataba de una acción política regalista, es decir, el rey actuaba como soberano que no reconocía superior en lo temporal y que, por tanto, tenía el derecho exclusivo para decidir en todos los aspectos de la monarquía, independientemente de la opinión de la Santa Sede 2 .

En un primer momento, el conjunto de propiedades que poseyeron los jesuitas se presumía cuantioso. Pedro Rodríguez Campomanes ${ }^{3}$ era muy claro en su Dictamen fis-

1. La realización del presente trabajo ha sido posible gracias a la concesión de una beca de investigación FPU entregada por el Ministerio de Educación y Ciencia bajo la referencia AP-2004-4990.

2. GIMÉNEZ LÓPEZ, Enrique: «La expulsión o el fin de los privilegios» en La Compañía de Jesús en España: otra mirada, Joaquín Morales Ferrer y Agustín Galán García (eds.), Madrid, 2007, pp. 93-106.

3. Pedro Rodríguez de Campomanes (1723-1802) fue licenciado en derecho, censor de la Academia de la Historia en 1753, asesor general de correos en 1755 y fiscal del Consejo de Castilla en 1762. Recibió el título de Conde de Campomanes en 1780. Se convirtió en el Presidente del Consejo de Castilla en 1786 y en Presidente de las Cortes en 1789. Para obtener más datos sobre su biografía ver CASTRO, Concepción 
cal señalando diferentes formas utilizadas por la Compañía de Jesús para enriquecerse. De esta manera aludía a la exención de diezmos, a determinados privilegios logrados de los Papas, a la acumulación de grandes cantidades de bienes conseguidos en los últimos años del reinado de Felipe II... El fiscal acusaba a los jesuitas de enviar a Roma enormes sumas extraídas de España e Indias, e iba más allá cuando indicaba que «el decantado celo de las misiones se esmera más en acumular los bienes temporales que en inspirar en los pueblos la fidelidad y la religión» ${ }^{4}$. Igualmente, señalaba que la Compañía de Jesús

"por acumular incesantemente riquezas degenera en las costumbres opuestas a su profesión, absorbe la sustancia de los pueblos, reduciéndolos a la esclavitud y enajenándolos de los soberanos legitimos, apoderándose, finalmente, a grandes pasos, de la soberanía misma» ${ }^{5}$.

No debemos olvidar que todavía era reciente la derrota en el Consejo Real del proyecto desamortizador de los fiscales Francisco Carrasco y el propio Campomanes. El fiscal del Consejo de Hacienda, Francisco Carrasco, había solicitado en una representación fechada en 1 de junio de 1764, la promulgación de una ley que limitase la adquisición de bienes inmuebles por parte de las manos muertas, es decir, por parte de la Iglesia, debido a los perjuicios derivados de su exención del pago de impuestos. No pretendía con ello mermar el patrimonio eclesiástico, ya que la medida afectaría a bienes que todavía no habían sido adquiridos por esta institución. Campomanes apoyó la postura de Carrasco y en 1765 publicó su Tratado de la regalía de amortización, una ampliación de la iniciativa presentada por este último. El proyecto, votado en junio de 1766, fue derrotado y suscitó una amplia oposición por parte del clero, la nunciatura y la Santa Sede 6 . La expulsión de los jesuitas de España representaba una oportunidad única de revancha tras el fracaso del plan desamortizador y un ensayo de ampliación del mercado de bienes inmuebles mediante la venta en subasta pública de las propiedades de la Compañía de Jesús ${ }^{7}$.

Una vez comenzado el proceso de extrañamiento y embargo de bienes, sorprendió la pobreza de ciertos colegios, contrariamente a lo que se pensaba en un principio,

de: Campomanes. Estado y reformismo, Madrid, 1996 y VALLEJo GARCíA-HEVIA, José María: La monarquía y un ministro, Campomanes, Madrid, 1997.

4. Rodríguez De CAmpomanes, Pedro, Dictamen fiscal de la expulsión de los jesuitas de España (17661767). Edición, Introducción y notas de Jorge Cejudo y Teófanes Egido, Madrid, 1977, pág. 118.

5. Íbidem, pág. 138.

6. TomÁs Y VALIENTE, Francisco: El marco político de la desamortización en España, Barcelona, 1977.

7. Yun CASAliLla, Bartolomé, «La venta de los bienes de las temporalidades de la Compañía de Jesús. Una visión general y el caso de Valladolid (1767-1808)» en Desamortización y hacienda pública, Tomo I, pp. 293-316 y ALBEROLA RomÁ, Armando y GiMÉNEZ LÓPEZ, Enrique: «Las temporalidades de la Compañía de Jesús en Alicante» Anales de la Universidad de Alicante. Historia Moderna, 2 (1982), pp. 167-210. 
pues las rentas de algunos de ellos, estando en un estado bastante apurado, ni siquiera alcanzaban para cubrir los gastos del camino ${ }^{8}$.

Se acordó la reunión del conjunto de capitales procedentes del embargo y administración de los bienes que pertenecieron a los jesuitas en la Depositaría general, una institución que se creaba en virtud de la Real Cédula de 2 de mayo de $1767^{9}$. El patrimonio incautado se utilizaría para hacer frente a los cuantiosos gastos ocasionados con el proceso de expulsión y a la satisfacción de una pensión vitalicia anual que se concedió a los regulares, pues a pesar de haber sido expulsados, continuaban siendo considerados como súbditos de Carlos III.

Con el pago de esta pensión se pretendía evitar cualquier tipo de reproche económico por parte del Pontífice a la hora de recibir a los más de 5.000 regulares que se le enviaban desde los dominios de Carlos III. Igualmente, serviría como un eficaz método de control de los jesuitas en el exilio. En ocasiones se les amenazaba con la pérdida de estos ingresos si actuaban en contra de los intereses españoles, aunque se podía dar el caso contrario, es decir, estimular a los miembros de la orden, doblando o triplicando las cantidades establecidas, en el supuesto de que realizasen labores beneficiosas a los intereses hispanos ${ }^{10}$.

En el momento de la ocupación de los colegios era necesaria la realización de un inventario que contuviese la totalidad de sus propiedades, prestando especial atención al cobro de las rentas y al pago de las cargas que llevasen adjuntas. Al principio sólo se debían vender aquellos bienes perecederos que pudiesen perderse. No obstante, en 1769, es decir, dos años después de la expulsión, se decidió sacar a la venta, mediante el método de la subasta pública, el resto de las pertenencias ocupadas, debido al deterioro que estaban experimentando y con la prohibición expresa de que «jamás pudiesen pasar á manos muertas»; con ello se pretendía que cayesen en manos de seglares contribuyentes y fuesen sometidas al pago de impuestos. Entre las posesiones de los regulares se establecieron algunas excepciones, pues los edificios materiales de las iglesias y capillas, sus ornamentos y vasos sagrados, viviendas, aulas y casas de estudio, no se pusieron en venta. Estos bienes quedaban reservados para el culto y la mayor conveniencia pública después de pasar el examen del Consejo Extraordinario, el

8. ISLA, José Francisco de: Historia de la Expulsión de los jesuitas. Memorial de las cuatro Provincias de España de la Compañia de Jesús desterradas del Reino a S.M. el Rey D. Carlos III, estudio introductorio y notas de Enrique Giménez López, Instituto de Cultura «Juan Gil-Albert», Diputación provincial de Alicante, 1999.

9. «Real Cedula, sobre crear Depositaria General para el resguardo y manejo de los caudales de los Jesuitas de España, é Indias, despues de su estrañamiento» en la Coleccion general de las providencias hasta aqui tomadas por el gobierno sobre el estrañamiento y ocupacion de temporalidades de los regulares de la Compañia, que existian en los dominios de S.M. de España, Indias, e Islas Filipinas á consecuencia del Real Decreto de 27 de febrero, y Pragmática-Sancion de 2 de abril de este año, Madrid, 1767, Parte primera, XIX, pp. 51-62.

10. FernÁNDEZ ARrillagA, Inmaculada: «El exilio de los jesuitas Andaluces» en La Compañia de Jesús en España: otra mirada, Joaquín Morales Ferrer y Agustín Galán García (eds.), Madrid, 2007, pp. 107128. 
tribunal más elevado en el proceso del destierro de los jesuitas. El Consejo era el encargado de elaborar consultas al monarca, mostrando su parecer y después de haber oído a los comisionados, obispos y fiscal, para que el soberano determinase las aplicaciones más convenientes a este tipo de pertenencias.

Estas propiedades serían aplicadas para aulas y habitaciones de maestros, pensión para estudiantes, traslado de universidades, convictorios, estudios generales, seminarios de nobles, niñas educandas, establecimientos de asistencia social... ${ }^{11}$ En cuanto a las alhajas y ornamentos sobrantes, se establecieron tres clases, distribuyendo los de primera clase entre las parroquias más necesitadas y procediendo a la venta de los de segunda y tercera clase.

El hecho de que el Consejo Extraordinario y el monarca, después de una cuidadosa reflexión, decidiesen los mejores destinos que se podrían dar a los edificios que poseyeron los jesuitas y que habían quedado excluidos del proceso de venta, no garantizaba su cumplimiento, especialmente cuando era necesaria la participación económica de algunos particulares que saldrían beneficiados. La falta de fondos fue una constante, así como recurrentes fueron los intentos de los interesados por conseguir que las temporalidades financiasen la totalidad de los gastos.

El problema, como se ha apuntado, es que las temporalidades eran finitas y estaban lejos de la idea que primeramente se tenía de ellas; no se debe olvidar que debían emplearse principalmente en la financiación de los gastos ocasionados con el proceso de extrañamiento y el pago de las pensiones vitalicias asignadas.

A pesar de todo, fueron muchos los que pretendieron obtener leña del árbol caído, por lo que la aplicación de estos edificios no siempre fue fácil, siendo numerosas las peticiones y súplicas de distintos colectivos o individuos particulares para beneficiarse de las posesiones que pertenecieron a los jesuitas. Permítasenos exponer como ejemplo el caso de Barcelona.

\section{LAS TEMPORALIDADES INMUEBLES URBANAS EN BARCELONA}

De todas las propiedades que poseían los jesuitas en la ciudad de Barcelona los siguientes inmuebles quedaban exentos del proceso de venta en subasta pública y, por lo tanto, debían someterse a la reflexión del Consejo Extraordinario para su aplicación más apropiada:

- La iglesia del Colegio de Belén.

- El colegio de Belén.

- La casa de ejercicios.

\subsection{La iglesia de Nuestra Señora de Belén}

Las celebraciones que se realizaban en la iglesia del colegio de Belén quedaron suspendidas súbitamente después de la expulsión de los jesuitas de la ciudad de

11. EGIDO, Teófanes: «La expulsión de los jesuitas de España» en Historia de la Iglesia en España, dirigida por Ricardo García-Villoslada, Madrid, 1979. 
Barcelona. Ante la nueva situación, el rector, la comunidad y los obreros laicos de la iglesia parroquial de Santa María del Pino, sita en la misma ciudad, aprovechando que la que perteneció al colegio de Belén se encontraba en su demarcación, solicitaron al Consejo, con fecha de 9 de julio de 1767, el usufructo de la misma junto con sus celebraciones, ornamentos, derechos y pertenencias. Pretendían con ello proporcionar una mejor asistencia al crecido número de fieles que concurrían a la del Pino ${ }^{12}$.

En esta línea, el obispo de Barcelona, José Climent ${ }^{13}$, consideraba de gran utilidad para los feligreses de Santa María del Pino el uso de la iglesia de Belén, al igual que indicaba ser «muy del agrado de Dios» el que se celebrasen cuanto antes las misas y festividades que habían sido fundadas en ella ${ }^{14}$. Sin embargo, el Capitán General, Conde de Ricla ${ }^{15}$, rechazaba la pretensión del rector considerando que, al estar las parroquias tan inmediatas, se produciría el aumento de la comunidad eclesiástica sin alivio de los fieles.

El Consejo Extraordinario celebrado en 22 de marzo de 1769, después de haber escuchado las diferentes opiniones al respecto y tras la meditación que la situación requería, determinó que la iglesia del colegio de Belén debería aplicarse para la erección de una nueva parroquia, distinta de la de Santa María del Pino, sin perjuicio de los patronatos particulares, pero teniendo siempre presente el patronato eminente y la protección inmediata que correspondía al soberano ${ }^{16}$. El obispo quedaba encargado de proceder a su desmembración y efectuar la nueva erección. No obstante, mientras se llevaba a cabo esta disposición, el Extraordinario opinaba que debía ponerse corriente el culto en ella, en calidad de adyutriz o sufragánea de la del Pino. Además, una vez que la iglesia de Belén hubiese quedado provista decentemente, el obispo, de acuerdo con el comisionado, debería proceder a efectuar el reparto de los ornamentos y alhajas de iglesia sobrantes entre otras parroquias más pobres ${ }^{17}$.

12. En las matrículas de aquel año se hallaban contenidos 14.883 feligreses; en AHN. Clero-Jesuitas, Leg. 161, exp. 1.

13. Josep Climent i Avinent, nació el 11 de marzo de 1706 en Castellón de la Plana. Se licenció en Filosofía y consiguió el grado de doctor en Sagrada Teología (1727). En 1728 se convirtió en repetidor o ayudante de cátedra, alcanzando una pavordía o beneficio mixto al año siguiente. Fue nombrado obispo electo de Barcelona el día 21 de julio de 1766. Tuvo un papel pacificador en la revuelta de los quintos (primavera de 1773) y al interceder contra algunos diputados que resultaron culpables se le abrió un expediente que llevó al Consejo de Castilla y al monarca a optar por su traslado a la diócesis de Málaga. No obstante, Climent optó por la renuncia al cargo en 1775, siendo sucedido por Gabino Valladares. Climent falleció en su ciudad natal el 28 de noviembre de 1781. En TORT MiTJANS, Francesc: El obispo de Barcelona Josep Climent i Avinent, Barcelona, 1978.

14. AHN, Clero-jesuitas, Leg. 161. José Climent a José Moñino, 22 de agosto de 1767.

15. Ambrosio de Funes Villalpando Abarca de Bolea, Conde de Ricla (1719-1780). Entre 1767 y 1772 fue Capitán General de Navarra y Cataluña. En febrero de 1772 fue nombrado secretario de Estado y del Despacho Universal de la Guerra. En CADALSO, José: «Estudios Autobiográficos y epistolarios», Edición de N. Glendinning y N. Harrison. Londres: Támesis, 1979. Pág. 191.

16. AHN, Clero-Jesuitas, Leg. 80, Copia de la Real Cédula para la aplicación y destino del colegio de Belén.

17. AHN, Clero-Jesuitas, Leg. 885, Consejo Extraordinario de 22 de marzo de 1769. 
Tres años después, en 1772, el Consejo realizó varias providencias para que la Junta Municipal de Barcelona informase al prelado de las pías memorias y fundaciones que habían sido concedidas para la dotación de la nueva iglesia, con sus rentas correspondientes. Igualmente le instaba para que hiciese concluir la casa que debía tener la nueva parroquia para uso del párroco, debiendo satisfacer su coste de los productos y rentas de temporalidades ${ }^{18}$.

En 1779 todavía no se había establecido la nueva parroquia, por lo que la iglesia de Belén se encontraba cerrada, con los perjuicios que ello conllevaba. Por ese motivo, el día 9 de abril, el rector y los catedráticos del seminario conciliar solicitaban el uso y el cumplimiento de las pías memorias fundadas en ella, mientras no se producía la erección de la nueva parroquia, con la facultad de que sus limosnas sirviesen de dotación para los catedráticos del mismo ${ }^{19}$. Esta solicitud sería aceptada al año siguiente ${ }^{20}$.

El tiempo pasaba y, en 1786, seguía sin verificarse la erección de la nueva parroquia, permaneciendo la iglesia de Belén cerrada y sin uso $^{21}$. El entonces obispo de Barcelona, Gabino Valladares ${ }^{22}$, indicaba la necesidad de tener abierta dicha iglesia para evitar los daños que la falta de ventilación podría ocasionar al edificio, a las ropas y a sus ornamentos ${ }^{23}$. Con la intención de remediar esta situación solicitaba su uso para la celebración de los aniversarios y misas fundadas en ella, alegando la conveniencia del restablecimiento del culto para consuelo de los fieles y para la propia conservación de la edificación. La Real Resolución de 11 de septiembre de 1787 mandaba el cumplimiento de la aplicación de la iglesia de Belén, quedando a la libre disposición del obispo para que la destinase a nueva parroquia ${ }^{24}$.

Sin embargo, no será hasta 1795 cuando se apruebe la erección de la esperada nueva parroquia y la verificación del nuevo curato con las rentas sobrantes de misiones ${ }^{25}$. Ante esta situación, el rector y los catedráticos del seminario conciliar de Barcelona, buscando un aumento de su salario, solicitaron que no se innovase lo man-

18. AHN, Clero-Jesuitas, Leg. 80, Comunicación a Tomás del Mello, 27 de junio de 1772.

19. AHN, Clero-Jesuitas, Leg. 161, Gabino Valladares a Juan Antonio Archimbaud, 26 de febrero de 1785.

20. AHN, Clero-Jesuitas, Leg. 80, Representación del fiscal de 21 de febrero de 1780.

21. AHN, Clero-Jesuitas, Leg. 80, Representación de Alejandro de Arroyo de Rojas, 18 de octubre de 1786.

22. Gabino Valladares Mesía, nació en Aracena, provincia de Huelva, el 25 de octubre de 1725, siendo elegido obispo de Barcelona el 11 de septiembre de 1775 y consagrado el 29 de octubre del mismo año en la iglesia de los dominicos de Santo Tomás de Toledo, por el arzobispo Francisco Antonio Lorenzana Butrón. Falleció el 13 de febrero de 1794. En GUITARTE IZQUIERDO, Vidal: Episcopologio español (1700-1867), Ayuntamiento de Castellón de la Plana, 1992, p. 92; citado en AsTORGANO ABAJO, Antonio: «Encuentro del Padre Arévalo con el inquisidor jansenista Nicolás Rodríguez Laso, en la Italia de 1788» en El Humanismo extremeño. Estudios presentados a las Segundas Jornadas organizadas por la Real Academia de Extremadura en Fregenal de la Sierra en 1997, Trujillo, 1998, pp. 381-401, nota a pie de página núm. 50 .

23. AHN, Clero-Jesuitas, Leg. 80, Gabino Valladares al Conde de Floridablanca, 19 de julio de 1786.

24. AHN, Clero-Jesuitas, Leg. 161, Representación de Eugenio de Llaguno, 5 de enero de 1796.

25. Capital que ascendía a 17.718 libras, 15 sueldos y 11 dineros. En Íbidem. 
dado en la Real Cédula de 21 de agosto de 1769, según la cual, las memorias y obras pías fundadas en la iglesia de Belén y las rentas de la congregación de estudiantes bajo la invocación de la Anunciación, se aplicarían para aumentar la dotación de los catedráticos del seminario tridentino ${ }^{26}$. El rey resolvería que, sin perjuicio de llevar a efecto la erección de la iglesia del colegio de Belén en parroquia, se atendiese en lo que fuese posible al rector y catedráticos. Para ello sería necesario formar una relación de las memorias y obras pías fundadas en dicha iglesia y, una vez hecho, destinar las que fuesen legítimas para que las cumpliesen el rector y maestros del seminario, de manera que les sirviesen como aumento de la dotación que recibían ${ }^{27}$.

\subsection{El colegio de Belén}

El Consejo Extraordinario de 21 de mayo de 1769 establecía que el seminario conciliar o tridentino, también llamado colegio del obispo, debería trasladarse al colegio que perteneció a los jesuitas en la ciudad de Barcelona, quedando completamente separado del colegio de Cordelles, que debía seguir sin novedad. El comisionado de temporalidades de Barcelona, Bernardo O'connor ${ }^{28}$, cumpliendo con lo mandado, concedió al obispo de la ciudad, José Climent, y a sus sucesores en la mitra, el edificio material del colegio de Belén. Por su parte, el obispo transfería el edificio que ocupaba con anterioridad el seminario tridentino para que quedase a beneficio de las temporalidades y fuese destinado a ampliación de hospicio o lo que más conviniese ${ }^{29}$.

La traslación efectiva tuvo lugar el día 10 de febrero de 1774. A partir de ese momento, el seminario conciliar ocupaba el edificio material del colegio con su huerto, patios, entradas y salidas, usos, servidumbres y demás derechos. Compartía recinto con el colegio de Cordelles, aunque ambos quedaron con separación e independencia. Cabe destacar que la traslación se realizó en calidad de concesión y no de permuta, por lo que el seminario adquiría la obligación de satisfacer las cargas o pensiones de censos que tuviese que pagar el colegio de Belén.

De acuerdo con las órdenes establecidas, debía colocarse el escudo de las Reales Armas en las puertas principales y otros lugares convenientes. Una vez realizado, podrían fijarse en un paraje inferior los escudos del obispo, a fin de conservar la memo-

26. AHN, Clero-Jesuitas, Leg. 161, Representación de Eugenio de Llaguno, 27 de febrero de 1796.

27. Íbidem.

28. Bernardo O'connor Phaly (1696-1780), natural de Irlanda, fue Comandante en el Regimiento de infantería de Irlanda desde 1724, Teniente Coronel desde 1741, caballero de la Orden de Santiago desde 1739 y comendador de Bedmar y Albánchez en dicha orden desde 1743 por sus méritos en la campaña de Italia; corregidor de Tortosa en 1755, gobernador militar de Pamplona en 1760, Teniente general en dicho año, corregidor de Lérida en 1761, corregidor de Barcelona entre 1761 y 1772, Capitán General interino de Cataluña en 1772, Capitán General de Castilla la Vieja en 1772, Capitán General de la costa de Granada en 1774, Conde de Ophalia desde 1776 y consejero del Consejo de Guerra entre 1779 y 1780. Agradecemos estos datos al profesor Enrique Giménez López.

29. La concesión tuvo lugar el día 4 de abril de 1771. AHN, Clero-Jesuitas, Leg. 80, Testimonio del notario Félix Veguer y Avellá de 24 de abril de 1784 y AHN, Clero-Jesuitas, Leg. 161, Escritura de cesión de la fábrica material del colegio de Belén, 4 de abril de 1771. 
ria del patronato del seminario tridentino. Los ornamentos y vasos sagrados no serían distribuidos por el momento, quedando a disposición del prelado para la realización del reparto correspondiente. Igualmente quedaba a disposición del obispo la biblioteca del colegio ${ }^{30}$.

Una vez establecido en el colegio que perteneció a los jesuitas, el seminario tridentino debía ocuparse de los estudios de teología, filosofía y gramática, mientras que el colegio de Cordelles se encargaría de las cátedras de latinidad y matemáticas para la instrucción de seculares. Las memorias u obras pías que habían sido fundadas en el colegio e iglesia de Belén, al igual que los efectos pertenecientes a la congregación de estudiantes, que debía cesar ${ }^{31}$, se destinarían para aumentar la dotación de los maestros del seminario tridentino ${ }^{32}$. La congregación de seglares de Nuestra Señora de la Natividad, que había sido fundada con anterioridad en el colegio, podría subsistir desarrollando sus actividades de asistencia a los enfermos pobres de los hospitales, pero para ello debería pasar a sala primera de gobierno, donde se le proporcionarían nuevas constituciones y estatutos.

Precisamente, dicha congregación realizó una representación al Consejo, con fecha de 17 de julio de 1767, en la que indicaba que después de la ocupación de temporalidades se habían embargado también sus ornamentos, efectos, libros, rentas y emolumentos, con lo que se vio impedida para continuar sus actividades ${ }^{33}$. Igualmente indicaba poseer un oratorio propio e independiente de la fábrica del colegio y dominio de los jesuitas, establecido por el Baile General en 1672, que también había sido ocupado, produciéndose el embargo de los ornamentos y alhajas que fueron proporcionados por los miembros de dicha congregación. Por todo ello solicitaba permiso para continuar sus ejercicios en el referido oratorio y la devolución de sus ornamentos, papeles, rentas y demás emolumentos propios ${ }^{34}$.

Ante la ausencia de noticias, se realizó una nueva súplica ante el rey, esta vez con fecha de 15 de abril de 1784, en la que se insistía en el carácter secular de la congregación y se indicaba que únicamente intervenía un jesuita en lo tocante a las funciones espirituales, pero que dicho papel podría ocuparlo cualquier otra persona eclesiástica secular o regular. De la misma manera, la concurrencia en el colegio de los expulsos era voluntaria y casual, pudiendo trasladarse a otro paraje y cesar la asistencia espiritual de los jesuitas. Asimismo, se señalaba que los ejercicios de la congregación habían

30. AHN, Clero-Jesuitas, Leg. 161, El conde del Asalto a José Payo Sanz, 10 de febrero de 1774.

31. La Real Cédula expedida en 14 de agosto de 1768 declaró por extinguidas todas las congregaciones o hermandades que hubiese establecidas en los colegios con el objeto de cortar cualquier recelo de fanatismo.

32. AHN, Clero-Jesuitas, Leg. 80, José Moñino al Consejo, 5 de agosto de 1771.

33. Sus ejercicios espirituales, la asistencia a los pobres enfermos de las cárceles reales, la limosna de las seis gallinas que suministraba diariamente al hospital general para la olla y caldo, y los alimentos a siete mujeres que tenía recogidas con la obligación de asistir y cuidar de los enfermos de dicho hospital.

34. AHN, Clero-Jesuitas, Leg. 161, Súplica de la congregación de la Natividad de María Santísima de 17 de julio de 1767. 
cesado desde el momento de la expulsión de la Compañía de Jesús, pues su oratorio estaba ubicado dentro de los muros del colegio, que se encontraba ocupado y cerrado por el corregidor de la ciudad. Al no poder reunirse, se dejaron de cobrar las rentas de las fundaciones y se dejó de intervenir en los fines a los que fueron destinadas dichas rentas.

Después de haber oído esta súplica, el Consejo acordó la devolución a la congregación de sus rentas y efectos, así como la realización de sus ejercicios devotos en el oratorio. Sin embargo, el obispo barcelonés se negó a desprenderse del citado oratorio y de sus alhajas y ornamentos, al considerar que le pertenecían, pues en el momento en que se produjo la traslación del seminario conciliar al colegio de Belén, estas propiedades figuraban incluidas en la escritura de posesión. La congregación indicó al obispo que se contentaría con usar el oratorio en los actos y ejercicios de su instituto que, excepto en los días de comunión, no incomodaría a los maestros y colegiales del seminario tridentino. No obstante, continuó la negativa del prelado ${ }^{35}$.

Ante esta situación, el Consejo acordó en 22 de abril de 1785 la entrega de los ornamentos, alhajas y papeles inventariados en el tiempo de la expulsión que pertenecían a la congregación. Al mismo tiempo ordenaba al obispo un informe de sus pretensiones para que dicha congregación pudiese continuar sus ejercicios en el oratorio sin alterar el gobierno del seminario, de manera que no se perjudicase a ninguno de los dos establecimientos $^{36}$.

Una vez que se hubo trasladado el seminario conciliar al colegio que poseyeron los miembros de la Compañía de Jesús, no resultó fácil la búsqueda de la aplicación más conveniente para el inmueble que dejaba vacante dicho seminario. En principio, se planteó la posibilidad de establecer allí un hospicio ${ }^{37}$. Sin embargo, el obispo Climent no coincidía con esta idea en su dictamen de 19 de septiembre de 1767, indicando que el edificio que ocupaba el seminario se encontraba separado materialmente de la casa de misericordia, por lo que para poder recoger allí a los pobres sería preciso multiplicar el número de oficinas y empleados. De la misma manera, consideraba que se trataba de un inmueble menos capaz que la casa de misericordia existente, la cual contenía cerca de mil pobres y podría extenderse si se le uniesen unas casas contiguas o parte del huerto ${ }^{38}$.

Por otro lado, el conde de Ricla, Capitán General de Cataluña, contemplaba de gran utilidad la creación de ese hospicio para limpiar la capital y los pueblos inmediatos del Principado de individuos que consideraba «perjudiciales al estado» ${ }^{39}$. No debemos olvidar que hubo quienes atribuyeron los motines que acontecieron en Madrid en 1766 al elevado número de vagos de la ciudad. Así, al considerar a este grupo

\footnotetext{
35. AHN, Clero-Jesuitas, Leg. 161, Solicitud de la Congregación de Nuestra Señora de la Natividad de 15 de abril de 1784.

36. AHN, Clero-Jesuitas, Leg. 161, Payo Sanz al obispo de Barcelona, 23 de abril de 1785.

37. AHN, Clero-Jesuitas, Leg. 161, Miguel Gómez a José Moñino, 22 de agosto de 1767.

38. AHN, Clero-Jesuitas, Leg. 161, José Climent a José Moñino, 19 de septiembre de 1767.

39. AHN, Clero-Jesuitas, Leg. 161, El conde de Ricla a José Moñino, 18 de septiembre de 1767.
} 
marginado como una posible amenaza y fácil comparsa en cualquier tipo de motín, se pretendió llevar a cabo la remodelación de la beneficencia madrileña para acabar con la mendicidad, convirtiéndose la capital en un modelo a seguir para otras ciudades. Sería preciso limpiar las calles de vagos y mendigos y clasificarlos en dos grandes grupos: vagos útiles (que podrían ser enviados al ejército) y mendigos. Este último grupo sería enviado a hospicios en los que se les enseñaría un oficio y se convertirían en artesanos o trabajadores capaces de mantenerse y de educar a sus hijos. ${ }^{40}$

El Ayuntamiento de Barcelona coincidía con la necesidad de la recogida de los pobres y señalaba que, a pesar de que con anterioridad se había puesto en práctica la reclusión de todo género de gentes bajas en el hospital y hospicio de misericordia, con el tiempo disminuyeron las limosnas de los que contribuían a su manutención, por lo que se hizo preciso la reducción de su número. Además, el consistorio iba más allá al proponer un proyecto general consistente en el establecimiento de casas de recogimiento en cada diócesis bajo el nombre de hospital u hospicio de misericordia ${ }^{41}$.

El fiscal Manuel Sisternes y Feliu ${ }^{42}$ compartía esta misma opinión al considerar que se podría obtener provecho de unos individuos que en el día eran inútiles y perjudiciales al Estado, al aplicarlos al trabajo o, simplemente, una vez recogidos, hacerles seguir un método de vida arreglado a las obligaciones de cristiano sin servir de mal ejemplo ${ }^{43}$.

A pesar de todo, el proyecto presentaba grandes dificultades debido a la falta de caudales y arbitrios y a la carencia de una casa en la que recogerlos, pues el hospital de Nuestra Señora de Misericordia contenía cerca de mil pobres y no era capaz de mayor número pues dormían «a tres y a cuatro por cama». Sin embargo, en opinión de Manuel Sisternes, se podría contemplar la ampliación del edificio al unirle dos casas que tenía contiguas ${ }^{44}$.

Por todo ello, el Consejo determinó en su dictamen que el espacio dejado por el seminario conciliar debía quedar a beneficio de las temporalidades para que se pudiera destinar «a ampliacion de Hospicio o lo que mas combenga».

\subsubsection{La situación de la enseñanza en Barcelona}

No cabe duda de que el destierro de los seguidores de Loyola tuvo un considerable impacto en la enseñanza. Algunos vieron una oportunidad única para llevar a cabo una reforma que condujese a una enseñanza más ilustrada. En otros, fue notable la preocupación ante lo que consideraban una acción que provocaría el estancamiento de los

40. CAStro, Concepción de: Campomanes. Estado y reformismo ilustrado, Madrid, 1996, pp. 198-201.

41. AHN, Clero-Jesuitas, Leg. 885, Consejo Extraordinario de 22 marzo de 1769.

42. Manuel Sisternes i Feliu (1728-1788), fue fiscal del crimen de la Real Audiencia de Cataluña entre 1766 y 1779. Con posterioridad se trasladó a Madrid donde se le nombró Alcalde de Casa y Corte. Más tarde recibió el título de Fiscal del Supremo Consejo y Cámara de Castilla y se convirtió en hombre de confianza del rey Carlos III.

43. AHN, Clero-Jesuitas, Leg. 885, Consejo Extraordinario de 22 marzo de 1769.

44. Íbidem. 
estudios. Éste fue el caso del obispo barcelonés José Climent, que en el dictamen que envió al Consejo Extraordinario indicando el mejor uso que se podía dar a las temporalidades de la ciudad, mostraba su preocupación por la enseñanza, haciendo hincapié en la necesidad de solucionar la decadencia de las letras que padecía la diócesis. Por ello, solicitaba el establecimiento de estudios que fuesen de utilidad para el seminario tridentino y para el colegio de Cordelles y la creación de sendas capillas u oratorios privados en los que llevar a cabo los actos espirituales de los colegiales. Recalcaba la necesidad de llenar el vacío dejado por los jesuitas en la enseñanza, pues de lo contrario sería todavía mayor el estancamiento de las ciencias, debido a que, a pesar del nombramiento de maestros de gramática, doctrina cristiana y primeras letras, las materias de teología, filosofía y matemáticas se encontraban sin profesores. A ello habría que añadir la circunstancia de que a la celebración de tres concursos de curatos para ocuparse de la teología dogmática y moral se habían presentado opositores que no alcanzaban el nivel deseado, por lo que se hacía necesario recurrir a religiosos ${ }^{45}$.

Igualmente se mostró preocupado por la enseñanza el obispo Gabino Valladares, que en 1776 realizó una súplica para que aquéllos que estudiaban en el seminario conciliar la filosofía y la teología escolástica pudiesen graduarse allí, en universidades aprobadas o, al menos, en la universidad de Cervera, pues la Real Cédula de 11 de marzo de 1771 produjo un considerable atraso en los estudios al impedir el paso de estos cursos para graduarse en las universidades ${ }^{46}$.

\subsubsection{El Seminario de nobles de Cordelles}

Como hemos indicado con anterioridad, el Seminario de nobles de Santiago de Cordelles se encontraba en el mismo recinto que el colegio de jesuitas de Nuestra Señora de Belén. No obstante, a pesar de coincidir espacialmente, no compartían propietario, ya que mientras que el Colegio de Belén pertenecía a las temporalidades jesuitas, el Seminario de nobles de Cordelles era propiedad de esa familia. Esta situación no debió de quedar muy clara a los comisionados de Barcelona, pues se confundió este edificio como parte de las temporalidades que pertenecieron a los regulares expatriados, lo que motivó el recurso del entonces patrono del seminario, D. Francisco Antonio de Copons Cordelles i Vilallonga, con el objetivo de aclarar la situación.

Para entender el origen de esta confusión hay que remontarse al año 1659, cuando el entonces patrono del seminario de nobles, D. Galcerán de Cordelles, otorgó una escritura de concordia mediante la cual transfería y encargaba al colegio de jesuitas de Belén de la ciudad de Barcelona la dirección y gobierno del colegio de Cordelles, pues los jesuitas habían adquirido el mayor crédito para la enseñanza y educación de la juventud. Esta escritura se realizó sin perjudicar ni disminuir el dominio, los derechos y las prerrogativas de la familia de Cordelles, que quedaban intactos, de manera que tanto la propiedad del colegio y sus rentas, como el derecho de patronato, con sus

45. AHN. Clero-Jesuitas. Leg. 161, José Climent a José Moñino. Barcelona, 19 de septiembre de 1767. 46. AHN. Clero-Jesuitas, Leg. 161, Súplica de Gabino Valladares de 31 de enero de 1776. 
facultades y prerrogativas, continuaban siendo privativos del patrono de dicha casa y de los colegiales de su linaje. Dicho acuerdo se prolongó hasta la época en la que los jesuitas fueron expulsados.

En ese momento, siendo patrono del citado seminario D. José de Copons, se procedió a la división de las dos edificaciones, por medio de peritos nombrados por una y otra parte, colocando en el extremo del edificio del colegio de la Compañía de Jesús el nombre del monarca y en la parte del colegio de Cordelles el nombre de esta familia. En principio no debió de existir ninguna confusión, pues a la muerte del patrono, su heredero, D. Francisco Antonio de Copons Cordelles i Vilallonga, tomó posesión de dicho colegio con el consentimiento del Capitán General del Principado de Cataluña, el conde del Asalto ${ }^{47}$, el día 28 de mayo de $1774^{48}$.

El problema apareció cuando en 1787 se envió un oficio al obispo de Barcelona para que informase del destino que podría darse al seminario de nobles de Cordelles ${ }^{49}$. Al año siguiente, el rey, decidido a que se llevase a efecto el destino acordado para dicho seminario, indicaba que debía subsistir el actual arriendo y

«que su producto liquido atendida la conserbacion del Edificio y demas rentas anuas [...] se invierta en la misma forma que VSI [el obispo] propone, a fabor de Estudiantes Parientes del fundador, y a falta de estos al de Huerfanos o Pobres de esa Ciudad y Obispado para el mismo fin de Estudios por no ser suficientes las rentas para que se mantengan colegiales. $»^{50}$

Para llevar a cabo esta aplicación era preciso que el obispo de Barcelona, junto con el comisionado de temporalidades y el patrono de la casa de Cordelles, hicieran expedir una escritura en la que constase la fundación primitiva del seminario y sus estatutos, los pactos realizados con los ex-jesuitas, una razón individual de las rentas y un memorial del patrono, debiendo quedar el colegio bajo el Real patronato e inmediata protección del monarca.

47. Francisco González de Bassecourt era conde del Asalto, marqués de González, de Grigny, de Borghetto y de Ceballos, comendador de Mirabel en la orden de Santiago, Teniente General de los Reales Ejércitos, Sargento Mayor, Inspector y Comandante del regimiento de guardias de infantería española, Gobernador militar y político de Barcelona y su distrito y comisionado de las temporalidades ocupadas a los jesuitas en Barcelona. Sustituyó al conde de Ricla como Capitán General de Cataluña cuando éste fue nombrado Secretario de Guerra (1773-1789). Para una mayor información sobre este personaje ver MERCADER, Joan: Els capitans generals, Barcelona, 1963, pp. 41, 104 y 109.

48. El acto de posesión se hizo de la siguiente manera:«teniendo en sus manos las llaves de las dichas Casas y Colegio (por haverselas entregado el Ilustre Señor Conde del Asalto, Gobernador Politico, y Militar de esta Ciudad) ha habierto las Puertas principales de las referidas Casas, y ha entrado en ellas, y quedando solo dentro de aquellas, ha cerrado las dichas Puertas, y saliendo despues de ellas, ha buelto a cerrar las mismas y se ha llevado las llaves de ellas: Todo lo que ha echo en senyal de dicha posesión». AHN, Clero-Jesuitas, Leg. 161, Acto de posesión del colegio de Cordelles por parte de Francisco Antonio de Copons de Cordelles i Vilallonga, 28 de mayo de 1774.

49. AHN, Clero-Jesuitas, Leg. 80, Oficio dirigido al Obispo de Barcelona de 12 de julio de 1787. 50. AHN, Clero-Jesuitas, Leg. 80, Oficio dirigido al Obispo de Barcelona de 26 de julio de 1788. 
Es en ese momento cuando se produce la súplica del patrono del seminario, Francisco Antonio de Copons Cordelles i Vilallonga, solicitando al rey la conservación del derecho de patronato, dominio y pertenencia a los herederos y descendientes de su linaje y familia, junto con las rentas del colegio. Para ello alegaba que D. Jaime de Cordelles, fundó el colegio de sus propios bienes, erigiendo un patronato hereditario perpetuo e inseparable del sucesor de la herencia de la casa de Cordelles. Todas las rentas que dejó se deberían aplicar exclusivamente a beneficio de estudiantes colegiales de su propio linaje, excluyendo a los que no perteneciesen al mismo. Copons señalaba que en el caso de que se invirtiesen las rentas del colegio a beneficio de extraños, huérfanos o pobres del obispado, como indicaba la providencia de la Dirección General de Temporalidades, se perjudicaría al linaje y familia de Cordelles y se iría en contra de la mente del fundador ${ }^{51}$.

No se debe olvidar que la Pragmática Sanción de 2 de abril de 1767, en su artículo tercero, indicaba que la ocupación de las temporalidades debía realizarse sin perjuicio de sus cargas y mente de sus fundadores ${ }^{52}$. Ello motivó que se creyese justo el recurso de Francisco Antonio de Copons Cordelles i Vilallonga al considerar que debía enmendarse la equivocación padecida, por ser indubitable que el colegio de Cordelles nunca había pertenecido a los regulares de la extinguida Compañía ${ }^{53}$.

\subsubsection{La súplica de la Academia de Ciencias Naturales}

La Real Academia de las Ciencias Naturales y Artes de Barcelona ${ }^{54}$ solicitó en 1786 la concesión del terreno comprendido entre el seminario tridentino y el colegio de nobles de Cordelles, indicando que el número de sus individuos crecía cada día, al igual que su colección de máquinas, instrumentos, libros y piezas de historia natural, de manera que se encontraba con suma estrechez en la habitación que se le concedió

51. AHN, Clero-Jesuitas, Leg. 161, Comunicación de Lorenzo Buxeda de 12 de noviembre de 1788.

52. Artículo III. Declaro, que en la ocupacion de temporalidades de la Compañia se comprenden sus bienes y efectos, asi muebles, como raíces, ó rentas Eclesiásticas, que legitimamente posean en el Reyno; sin perjuicio de sus cargas, mente de los Fundadores, y alimentos vitalicios de los Individuos, que serán de cien pesos, durante su vida, á los Sacerdotes; y noventa á los Legos, pagaderos de la masa general, que se forme de los bienes de la Compañia.

53. AHN, Clero-Jesuitas, Leg. 161, La Dirección General de Temporalidades a Francisco Antonio de Copons Cordelles i Vilallonga, 7 de febrero de 1789.

54. La Academia de Ciencias Naturales y Artes de Barcelona se originó en el entorno de la clase de matemáticas que el jesuita Tomàs Cerdà profesaba en el colegio de Cordelles, comenzando bajo la denominación de «Conferencia físico-matemática-experimental» y siendo su director Francesc Subirás y su secretario perpetuo Joan Antoni Desvalls, quien se convertiría con posterioridad en marqués de Llupià y sería el auténtico alma de la institución. En 1765 fue oficialmente erigida Real Academia bajo la providencia del Capitán General marqués de la Mina. La Academia se encontraba dividida en diferentes secciones entre las que destacaban las siguientes: algebra y geometría, hidrostática y meteorología, electricidad y magnetismo, botánica, química y agricultura. En MERCADER, Joan, Els capitans generals, Barcelona, 1963, pp. 146-147. 
para su establecimiento ${ }^{55}$. La Academia estaba interesada en ese edificio aunque no presentaba una buena disposición, al estar encerrado entre el colegio y el seminario, y a pesar de que se trataba de un inmueble caracterizado por su limitada extensión de anchura respecto a su longitud. Sin embargo, su fábrica era suficiente para la ejecución de su plan, pudiendo establecerse el jardín botánico en el huerto, un laboratorio químico en sus extremos y, en los diferentes pisos, se podrían ubicar los gabinetes de artes y de historia natural, los armarios de máquinas e instrumentos, la biblioteca, la sala de juntas y la clase de matemáticas. El coste de toda la obra se calculó en treinta o treinta y cinco mil reales de ardites ${ }^{56}$.

El Consejo accedió a esta solicitud, sin embargo, no le ofrecía una concesión libre y en absoluta propiedad, sino que se trataba de una cesión por vía de establecimiento, debiendo pagar la Academia una corta cantidad de entrada ${ }^{57}$ y un leve censo anual de 2 reales de vellón que asegurase los laudemios y el dominio directo del monarca ${ }^{58}$.

El 30 de agosto de 1786 se otorgó a la citada Academia la escritura de establecimiento del edificio y huerto entre el seminario tridentino y el de Cordelles ${ }^{59}$ y se establecía la condición de que en el caso de extinguirse o mudarse a otro paraje, debería restituirlos íntegramente a las temporalidades ${ }^{60}$.

Por consiguiente, la Academia quedó establecida en el edificio concedido. Limitaba a la izquierda con el colegio de Cordelles, a la derecha con el seminario tridentino y a su espalda con un almacén en el que se colocaban las maderas que no cabían en las atarazanas, mientras no se construía en sus inmediaciones un tinglado que tenía proyectado el comandante de artillería ${ }^{61}$.

\subsection{La casa de ejercicios}

La casa de ejercicios que perteneció a los padres de la Compañía de Jesús en la ciudad de Barcelona, se encontraba inmediata al colegio de Belén y fue pretendida por diversos grupos que proyectaban distintos usos para su fábrica:

55. AHN, Clero-Jesuitas, Leg. 161, El barón de la Linde al Conde de Floridablanca, 8 de abril de 1786.

56. AHN, Clero-Jesuitas, Leg. 161, Relación y tanteo del coste para trasladar la Academia de Ciencias Naturales y Artes de Barcelona, 7 de abril de 1786.

57. Establecida en 40 reales de vellón.

58. AHN, Clero-Jesuitas, Leg. 161, El barón de la Linde al Conde de Floridablanca, 8 de abril de 1786.

59. AHN, Clero-Jesuitas, Leg. 161, El barón de la Linde a Juan Antonio Archimbaud y Solano, 9 de noviembre de 1786.

60. En un principio, la escritura de establecimiento indicaba que en caso de extinguirse la Academia o mudarse a otro paraje, debía restituirse dicha casa y huerto a la Real Hacienda. Pronto la Real Dirección de Temporalidades solicitaba la enmienda del error, pues el Rey había ordenado la separación de los fondos de temporalidades de los de la Real Hacienda y, como el edificio y huerto cedido a la Academia era de las temporalidades, a ésta correspondían los 40 reales de entrada y los dos de censo anual. Igualmente, en caso de extinción o traslado, la casa y el huerto debían restituirse íntegramente a las temporalidades y no a la Real Hacienda. Sin embargo, en una carta dirigida a Jerónimo Girón en 1790 se indica no constar que se haya producido la enmienda del error.

61. AHN, Clero-Jesuitas, Leg. 161, El barón de la Linde al Conde de Floridablanca, 8 de abril de 1786. 
- La congregación de María Santísima de la Esperanza y Salvación de las almas, sita en la misma ciudad, consideraba este edificio como el lugar más apropiado para trasladar una casa de recogimiento que se había fundado en el año 1744 para recoger a las prostitutas que determinasen mejorar su vida. Sin embargo, el número de las mismas se fue incrementando con el tiempo, por lo que el inmueble primero dejó de ser capaz de acogerlas a todas, regresando muchas de ellas a su mala vida ${ }^{62}$.

- El Hospital General de Santa Cruz de Barcelona solicitaba que se trasladase a la casa de ejercicios la cárcel de la galera, en la que residían las mujeres sentenciadas por la sala del crimen de aquella Real Audiencia. Pretendía con ello utilizar el terreno que ocupaba la mencionada cárcel para ensanchar su fábrica ${ }^{63}$.

- El comisionado de temporalidades consideraba muy recomendable la continuación del ministerio de ejercicios espirituales.

- El Capitán General, conde de Ricla, en su intento de crear un hospicio general en Barcelona para recoger a todos los mendigos del Principado de Cataluña, solicitó el edificio como el lugar más indicado ${ }^{64}$.

El Consejo Extraordinario, en su reunión de 22 de marzo de 1769, acordó que la casa de ejercicios se aplicase a la de recogimiento de mujeres perdidas, destinando la que éstas ocupaban para cárcel de la galera y el terreno de esta última para la extensión del Hospital General. Los gastos necesarios para poner corriente el uso de estos inmuebles debían correr de cuenta de los interesados, sin gravamen de las temporalidades.

Por su parte, las memorias que hubiese en la casa de ejercicios se deberían cumplir en el seminario tridentino, aplicándolas para aumento de la dotación de sus maestros y directores, y distribuyendo el obispo, de acuerdo con el comisionado, las alhajas $\mathrm{y}$ ornamentos de su iglesia entre parroquias pobres ${ }^{65}$.

Las temporalidades asumieron los gastos que el Consejo había determinado y se produjo la traslación de la casa de mujeres arrepentidas a la de ejercicios. Sin embargo, la cárcel de la galera no se pudo trasladar al edificio que ocupó la casa de mujeres arrepentidas por falta de fondos para costear las obras. El Consejo, con fecha de 28 de noviembre de 1770, mandaba que los trabajos necesarios, que ascendían a 10.000 libras, debían correr de cuenta de la cárcel de la galera, por no ser posible a las temporalidades afrontar dicho pago. No obstante, indicaba que en caso de no poder asumir dicho coste, debería ubicarse allí el Hospital de Santa Cruz, entendiéndose como subrogación del edificio con el que se le había agraciado, es decir, el Hospital, en lugar de ocupar el terreno de la cárcel de la galera debería instalarse en el espacio que dejaba vacante la casa de mujeres arrepentidas ${ }^{66}$.

62. AHN, Clero-Jesuitas, Leg. 885, Consejo Extraordinario de 22 de marzo de 1769.

63. AHN, Clero-Jesuitas, Leg. 161, Ignacio de Castells a José Moñino, 2 de septiembre de 1767.

64. AHN, Clero-Jesuitas, Leg. 885, Consejo Extraordinario de 22 de marzo de 1769.

65. Íbidem.

66. AHN, Clero-Jesuitas, Leg. 80, Comunicación a Bernardo O'connor Phaly de 28 de noviembre de 1770 y Comunicación a José Faustino Pérez de Hita de la misma fecha. 
Pronto la Real Audiencia representó que la cárcel de la galera no disponía de efectos con los que costear las obras de su traslado. Por otra parte, el Hospital consideraba que la casa que ocuparon las mujeres arrepentidas no tenía la suficiente extensión y se encontraba muy distante, por lo que indicaba no convenirle dicho edificio. No obstante, señalaba que el inmueble de la cárcel de la galera era ideal para servirle de ensanche debido a su inmediatez. Ante estas circunstancias el Consejo pidió a la Real Audiencia una propuesta que contemplase las diferentes opciones con las que conseguir caudales para costear la obra ${ }^{67}$. Con fecha de 8 de febrero de 1772, la Real Audiencia exponía no hallar ningún arbitrio que proponer, pero indicaba su conformidad con la entrega de la casa de mujeres arrepentidas al Hospital ${ }^{68}$.

La Junta provincial consideraba que el Hospital debería trasladarse a la casa de mujeres arrepentidas, pero le parecía justo concederle la facultad de trasladar la cárcel de la galera a un edificio competente y, en ese caso, beneficiarse del inmueble que ésta ocupaba $^{69}$.

En 1782, el Hospital de Santa Cruz todavía no había ocupado el edificio que se le había concedido, sin duda, al no convenirle la distancia y extensión de dicho inmueble como había manifestado con anterioridad. Muestra de ello fue la pretensión de José Ruiz de Castañeda, oficial de la tesorería del Ejército y Principado de Cataluña, por adquirir una casa de las temporalidades que

«se halla sumamente derruhida, y para repararla, se necessitan a lo menos unas veinte mil Libras de Ardites, que equivalen en vellon á: 215.126 reales; cada dia va deteriorandose mas y en breve tiempo podrá contarse enteramente inutilizada. ${ }^{70}$

En un principio, el fiscal no encontró ningún inconveniente en que se admitiera la postura de Castañeda, siempre que se tasase su valor y se sacase en subasta pública. El Consejo llegó incluso a acceder a la petición del fiscal el día 1 de junio de 1782. Sin embargo, pronto se dieron cuenta del error y se desestimó finalmente la pretensión de Castañeda, pues aunque éste hubiera supuesto que era una casa de temporalidades sin destino, en cuyo caso se hubiese admitido su proposición, se trataba de la casa que el Consejo concedió al Hospital de Santa Cruz al no haber podido trasladarse allí la cárcel de la galera ${ }^{71}$.

\section{LAS ALHAJAS Y ORNAMENTOS DE IGLESIA}

Al igual que los inmuebles que hemos comentado a lo largo de este trabajo, las alhajas y ornamentos de iglesia y sacristía constituían otra de las excepciones en el proceso de venta de bienes, pues debían inventariarse y quedar custodiadas. En un principio, la Real Cédula de 24 de agosto de 1769 señalaba que, una vez efectuada la

67. AHN, Clero-Jesuitas, Leg. 80, Comunicación a Juan de Peñuelas de 20 de septiembre de 1771.

68. AHN, Clero-Jesuitas, Leg. 885, Consejo Extraordinario de 8 de junio de 1775.

69. Íbidem.

70. AHN, Clero-Jesuitas, Leg. 161, Representación de José Ruiz de Castañeda de 21 de agosto de 1781.

71. AHN, Clero-Jesuitas, Leg. 161, Representación de 17 de junio de 1782. 
decente provisión de la iglesia de Belén, el obispo y comisionado de temporalidades deberían repartir el sobrante de alhajas entre las parroquias pobres de la diócesis ${ }^{72}$. Debía protegerse conjuntamente la totalidad de los ornamentos, sin embargo, el 6 de marzo de 1773 se mandó la división de las alhajas en tres clases diferenciadas con el fin de evitar abusos o extravíos:

- Las de primera clase serían aquéllas que tenían contacto físico e inmediato con lo más sagrado de la religión. Se trataba de cálices, patenas, custodias y viriles en los que se exponía el sacramento, copones y adornos de reliquias.

- La segunda clase estaría integrada por los ornamentos destinados al culto para las funciones ordinarias o solemnes. Nos referimos a vinajeras con sus platillos, sacras palabras y evangelios, candeleros de altar, lámparas empleadas cotidianamente en el sacramento, adornos de imágenes y santos, coronas, diademas, laureolas y otras semejantes.

- A la tercera y última clase correspondían las alhajas que ni tenían contacto físico con lo sagrado ni eran necesarias para el culto, sino que servían para ensalzarlo y contribuir a su mayor pompa. Fuentes, bandejas, floreros, ramilletes, aparadores, jarras, arañas, blandones y otras riquezas semejantes componían esta categoría. ${ }^{73}$.

Las alhajas correspondientes a la primera clase se reservaban para el reparto entre parroquias pobres, mientras que las de segunda y tercera clase deberían venderse. Algunas alhajas pertenecientes a la segunda clase quedaban exceptuadas del proceso de venta y se establecía la preferencia en la compra por parte de las iglesias de las diócesis en las que existieron colegios de jesuitas ${ }^{74}$.

En el caso de la ciudad de Barcelona, el empleado del Real Monte Pío, José Miró y Pérez, indicaba a Campomanes en julio de 1782 que las alhajas pertenecientes al colegio de Belén, las cuales eran de un valor considerable, se encontraban depositadas en tres grandes arcas sin que se les hubiese dado ningún destino. Le resultaba extraño que una riqueza tan crecida estuviese en el olvido. Por ello se lo hacía saber al fiscal, pues era conocedor de que se habían dado varias disposiciones sobre la venta de los bienes de los expulsos y consideraba sorprendente que un valor tan crecido estuviera sumergido en un depósito ${ }^{75}$.

En atención a esta representación, el Consejo mandaba en 20 de mayo de 1783 que las Juntas provincial y municipal cumpliesen, sin pérdida de tiempo, lo mandado en las órdenes circulares de 30 de diciembre de 1774 y 28 de febrero de 1782, proce-

72. AHN, Clero-Jesuitas, Leg. 161, Gabino Valladares a Juan Antonio Archimbaud, 26 de febrero de 1785.

73. «Real Provision de Su Magestad, y Señores del Consejo, en el Extraordinario, para que los Comisionados en la ocupacion de Temporalidades de los Regulares de la extinguida Compañía de España, Indias, é Islas Filipinas procedan á la separacion de Ornamentos, Vasos Sagrados, y Alhajas de oro y plata, encontradas en las Iglesias que fueron de dichos Regulares, dirigiendo listas, y otras cosas» en Coleccion general de las providencias... Parte cuarta, XXXV, pp. 64-70.

74. AHN, Clero-Jesuitas, Leg. 161, Gabino Valladares a Juan Antonio Archimbaud, 26 de febrero de 1785. 75. AHN, Clero-Jesuitas, Leg. 161, José Miró y Pérez a Campomanes, 13 de julio de 1782. 
diendo al reparto de las alhajas de primera clase y la venta de las de segunda y tercera clase, poniendo su producto en arcas reales ${ }^{76}$.

Más adelante, se dio la orden de remitir a la corte las alhajas de oro y plata que estuviesen depositadas en el Real Monte Pío de Barcelona, a fin de darles su correspondiente destino. Atendiendo a esta situación, el obispo de Barcelona, Gabino Valladares, escribía a Juan Antonio Archimbaud en 26 de febrero de 1785, solicitando la suspensión de dicha orden. Alegaba para ello las órdenes reales que mandaban la distribución y venta de las alhajas en las respectivas diócesis, añadiendo que sería muy doloroso su reparto entre iglesias menos acreedoras y necesitadas, siendo quizás desconocidas de los fieles que hicieron donaciones gratuitas o limosnas para su fabricación ${ }^{77}$.

Igualmente, el prelado justificaba la situación por la cual no se había dado el destino correspondiente a las alhajas indicando lo siguiente: el Consejo Extraordinario había aplicado la iglesia de Belén para la erección de una nueva parroquia distinta de la de Nuestra Señora del Pino, pero cuando dicho obispo accedió a la diócesis en 1775, todavía no se había llevado a efecto, por lo que, dispuesto a cumplirla, formalizó el expediente necesario. Sin embargo, cuando se iba a dar la providencia de erección de la nueva parroquia, se comprobó la inexistencia de fondos para la necesaria dotación del cura y demás ministros que debían servirla. El obispo hizo presente la situación al Consejo en 20 de agosto de 1777, proponiendo algunos fondos ${ }^{78}$ que no merecieron la aprobación del Supremo Tribunal, por lo que dicha erección quedó suspensa. De esta manera, al estar suspendido el destino de la iglesia lo estuvo también el de la distribución de alhajas, pues debería realizarse una vez provista decentemente la nueva parroquia. En cuanto a las alhajas de segunda y tercera clase, no se había procedido a su venta por haber surgido algunas dudas acerca de las que eran vendibles y las que debían reservarse para ser repartidas. La Junta Municipal consideraba aceptable la venta de los adornos de reliquias y diferentes imágenes, al contrario que el obispo, que opinaba que deberían reservarse para los repartos ${ }^{79}$.

Archimbaud le contestaría en marzo de ese año, ordenando la realización de una lista que incluyese el conjunto de los vasos sagrados y las alhajas de oro y plata que deberían repartirse entre las parroquias pobres de la diócesis, para proceder a ello una vez aprobado por dicha Real Dirección. En cuanto a las alhajas de oro y plata cuya venta se encontraba dudosa, el obispo debería dar orden para la averiguación de su valor intrínseco según la ley de la plata u oro. Posteriormente lo debería comunicar a la Dirección para que se providenciase lo más conveniente ${ }^{80}$.

En 10 de febrero de 1783 se nombró al platero Joaquín Quadras para que pesase y tasase las alhajas de oro y plata que pertenecieron a los jesuitas, y cuya venta se hallaba

76. AHN, Clero-Jesuitas, Leg. 161, José Payo Sanz al Conde del Asalto, 24 de mayo de 1783.

77. AHN, Clero-Jesuitas, Leg. 161, Gabino Valladares a Juan Antonio Archimbaud, 26 de febrero de 1785.

78. Su antecesor, José Climent, expuso la posibilidad de aplicar a dicho destino algunas rentas de las que dejó doña María de Camporells para la realización de obras pías.

79. AHN, Clero-Jesuitas, Leg. 161, Gabino Valladares a Juan Antonio Archimbaud, 26 de febrero de 1785. 80. AHN, Clero-Jesuitas, Leg. 161, Archimbaud a Gabino Valladares, 12 de marzo de 1785. 
dudosa. El obispo, Gabino Valladares, escribió a la Real Dirección en 15 de junio de 1785, indicando el destino que se les podría dar e incluyendo un informe sobre la aplicación de las que se consideraron exceptuadas de la venta, para que dicha Dirección lo aprobase ${ }^{81}$.

La Real Dirección escribió al obispo en 6 de julio indicando que se procediese a la venta de las alhajas que estaban dudosas, al no haber peligro de que se causasen irreverencias ni de que se maltratasen los cuerpos o reliquias de los santos. Igualmente, debería proceder a la distribución de las no vendibles entre las iglesias propuestas por el mismo prelado ${ }^{82}$. No obstante, antes de llevar a cabo la venta del conjunto de alhajas custodiadas en el Monte de Piedad de Barcelona, se eligió al platero contraste Nicolás Regés, para su peso y valoración, que realizó en 26 de agosto de 1785 indicando que el conjunto de las alhajas importaba 7.612 libras, 18 sueldos y 9 dineros ${ }^{83}$.

El día 29 de agosto de 1785 tuvo lugar la subasta pública de las alhajas vendibles que pertenecieron a los jesuitas y estaban custodiadas en las casas del Real Monte de Piedad de Barcelona.

El 7 de diciembre, Alejandro de Arroyo de Rozas ${ }^{84}$, siendo entonces presidente de la Junta Municipal de Barcelona, escribía a la Real Dirección para indicar que se vendieron todas las alhajas de plata, con excepción de dos lámparas, por ser dotación de las capillas del Santo Cristo y san Rafael de la iglesia de Belén, que al ser de dotación particular de dichas capillas, se entregaron al obispo (al igual que una lámpara que se le entregó para el altar mayor de la iglesia de Belén) y no se pudo depositar su importe en manos de Francisco de Milans, como comisionado del Banco Nacional de San Carlos, al no haber querido éste aceptar dicha partida ${ }^{85}$.

Alejandro de Arroyo de Rozas dirigió a la Real Dirección una carta de pago dada por el tesorero general de ese ejército, Blas González, de fecha de 25 de febrero de 1786, a favor de Francisco Alberch, alguacil mayor de juzgado, nombrado para el cobro y responsabilidad de lo que resultó de la venta de las alhajas de plata vendibles que estaban custodiadas en el Real Monte de Piedad, por cantidad de 71.730 reales y 12 maravedíes de vellón equivalentes a 6.668 libras, 13 sueldos y 8 dineros de ardites,

81. AHN, Clero-Jesuitas, Leg. 161, Gabino Valladares a Archimbaud, 15 de junio de 1785.

82. Entre las iglesias que debían recibir parte de estas alhajas se encontraban las de Nuestra Señora del Pino, San Jaime, San Miguel, San Cucufate, la del hospital de misericordia, la del Real Hospicio, la capilla del seminario conciliar, la de San Julián del Arbos, la de Santa María de Villarrodosa y la de San Andrés de Alfar, en AHN, Clero-Jesuitas, Leg. 161, Estado de las alhajas que se hallaron en la iglesia del colegio de Belén, 14 de abril de 1785.

83. AHN, Clero-Jesuitas, Leg. 161, Andrés de Ciria a Archimbaud, 7 de septiembre de 1785.

84. Alejandro de Arroyo de Rozas, originario de Cantabria, ingresó en el ejército como cadete en 1728, participando en la conquista de Orán en 1732 y en las dos últimas expediciones italianas. Ascendió a brigadier en 1774 y a mariscal de campo en 1779. Obtuvo el gobierno militar de la ciudadela de Barcelona en 1781 y el militar y político de Lleida en 1783. Pasó al gobierno militar y político de Barcelona en agosto de 1785, convirtiéndose en corregidor de Barcelona el 27 de septiembre de 1785. Se retiró en 1789. En GAY ESCODA, Josep Maria: El corregidor a Catalunya, Madrid, 1997, pp. 570-571 y 601-602.

85. AHN, Clero-Jesuitas, Leg. 161, Alejandro de Arroyo de Rozas a Archimbaud, 7 de diciembre de 1785. 
que es lo que quedó líquido, una vez pagado el coste preciso que se causó con motivo de la venta ${ }^{86}$.

\section{CONCLUSIONES}

Cuantiosos fueron los intereses económicos que traía aparejada la marcha de los jesuitas. Con el conjunto de sus pertenencias se pretendía sufragar el monto de los gastos del proceso de su expatriación, pero a la vez, se trataba de una oportunidad única para acceder a un conjunto valioso de propiedades que habían estado fuera del mercado hasta ese momento. Las mejores de sus posesiones urbanas, exentas de los procesos de subasta, se destinaron para ser aplicadas con la mayor utilidad pública posible. Así, en la ciudad de Barcelona, el colegio que poseyeron los expulsos se destinó para el traslado del seminario conciliar. Igualmente, del destierro de los seguidores de San Ignacio se benefició la Academia de Ciencias Naturales, con su traslado al recinto del que fue colegio de Belén. La casa de ejercicios de los regulares se aplicó para el recogimiento de las «mujeres perdidas» de la ciudad y, finalmente, se proyectó la erección de una nueva parroquia en la iglesia que perteneció a los miembros de la orden ignaciana.

$\mathrm{Si}$ bien las intenciones seguidas en el proceso de aplicación de las temporalidades siempre fueron piadosas y trataron de mejorar algunos aspectos públicos que así lo requerían, como hemos visto, no siempre se llegaron a materializar o lo hicieron tarde. En uno u otro caso, el denominador común fue el mismo, la falta de fondos con los que hacer frente a los gastos necesarios para la adaptación de los edificios a su nuevo destino. En el caso barcelonés quedaba patente en la imposibilidad de trasladar la cárcel de la galera al terreno que ocupó la casa de ejercicios de los jesuitas, y la no utilización de ese mismo lugar como ensanche para el Hospital General. Además, el principal inconveniente para la construcción del hospicio que debía construirse en el terreno que dejaba vacante el seminario conciliar con su traslación, era, igualmente, la falta de fondos. En el caso de la iglesia que perteneció al colegio de Belén, no fue hasta 1795, es decir, 26 años después de la Real Cédula para su aplicación, cuando se aprobó la erección de una nueva parroquia en su lugar, pues fue en ese momento cuando se destinaron los fondos suficientes para hacer frente a los gastos de la obra. Este retraso conllevó la demora en el reparto de las alhajas sobrantes, ya que hasta que no estuviesen concluidos los trabajos no se podría determinar el excedente de ornamentos, debido a que antes de proceder a su distribución, la nueva parroquia debía quedar provista con toda decencia.

No dejan de llamar la atención las equivocaciones acontecidas en el proceso de embargo de bienes. Los casos más claros son el de la ocupación de las propiedades pertenecientes a la congregación de seglares de Nuestra Señora de la Natividad y el del intento de aplicación del Seminario de nobles de Santiago de Cordelles. En ambos casos, el Consejo Extraordinario reconoció los errores cometidos y dictaminó la restitución de las posesiones a sus legítimos dueños.

86. AHN, Clero-Jesuitas, Leg. 161, Alejandro de Arroyo de Rozas a Archimbaud, 8 de marzo de 1786. 
En resumen, las temporalidades jesuitas se encontraban muy distantes de la idea generalizada que se tenía de ellas; la falta de fondos con los que llevar a cabo las útiles aplicaciones proyectadas para los edificios que los expulsos dejaron vacantes con su marcha, ponía de manifiesto que las supuestas riquezas de los jesuitas tenían un componente más cercano al mito que a la realidad. 